\title{
Styloid Process Elongation and Calcification in Subjects with TMD: Clinical and Radiographic Aspects
}

\author{
Kelly Machado de ANDRADE \\ Carolina Almeida RODRIGUES \\ Plauto C. Aranha WATANABE \\ Marcelo Oliveira MAZZETTO \\ Department of Restorative Dentistry, Ribeirão Preto Dental School, \\ USP - University de São Paulo, Ribeirão Preto, SP, Brazil
}

\begin{abstract}
Knowledge of the Eagle's syndrome shows that its symptoms can be very easily confused with other types of craniomandibular disorders, especially temporomandibular disorders (TMD). The aim of this study was to find a possible correlation between the presence of TMD and elongation of the styloid process as well relate to presence of calcification of the stilohyoid chain. Fifty patients with TMD, confirmed from the RDC/TMD, were examined clinically and radiographically. Radiographic documentation consisted of digital panoramic radiograph and digital lateral cephalometric radiograph. Radiocef software (Radiomemory) was used for the analysis of radiographs by means of specific cephalometric tracing and linear measurements of the styloid process. Each radiograph was traced and measured three times with intervals of 1 month to spread the error. Statistical analysis was performed by Pearson's test $(\mathrm{p}=0.001)$ using Biostat 4.0 statistical software. Result showed an incidence of $76 \%$ elongation of the styloid process in the sample. There was a correlation between the bilateral measures taken in panoramic radiographs $(p<0.001)$ and also for measures of styloid process length carried out in different panoramic radiographs and lateral cephalometric radiographs $(p<0.001)$. It was concluded that there is prevalence of elongated styloid process in patients with TMD. However, no relationship was found between measurements on the stylohyoid chain and symptoms of headache, orofacial pain, tinnitus and vertigo.
\end{abstract}

Key Words: styloid process, temporomandibular disorders, orofacial pain, Eagle's syndrome, calcification.

\section{INTRODUCTION}

There has been an increasing percentage of patients with orofacial pain and temporomandibular disorders (TMD). It is believed that $40-75 \%$ of the population have at least one sign of TMD and $33 \%$ present at least one symptom $(1,2)$.

TMD is a collective term that encompasses a large number of clinical problems involving the masticatory muscles and/or temporomandibular joint (TMJ) (3). It generates a large number of signs and symptoms that are often similar to other disorders or diseases. Among the most common signs and symptoms of TMD are pain in the TMJ region or preauricular region, limited or asymmetric mandibular movements, joint noises and sounds, referred pain, headaches, tinnitus, earaches, vertigo/dizziness, feeling of ear fullness, hypoacusis and hyperacusis $(4,5)$.

Eagle's syndrome is still little known among dentists. It consists on anatomical changes in the styloid process or stylohyoid ligament, which can lead clinical manifestations similar to TMD. However, as not all morphological changes in the styloid process produces painful symptoms, the diagnosis of Eagle's Syndrome, resulting in elongation of the styloid apophysis is quite difficult. Most clinicians have no experience in this diagnosis and ultimately attribute the symptoms to other causes. Misdiagnosis hinders treatment success (6) since TMD is treated with conservative and reversible therapy, while the treatment for Eagle's syndrome can involve surgical excision. Several studies have shown that panoramic radiograph and detailed clinical

Correspondence: Prof. Dr. Marcelo Oliveira Mazzetto, Departamento de Odontologia Restauradora, Faculdade de Odontologia de Ribeirão Preto, USP, Av do Café S/N, 14040-904 Ribeirão Preto, SP, Brasil. Tel: +55-16-3602-4087. Fax: +55-16-3602-4781. e-mail: mazzetto@forp.usp.br 
history should be obtained for the adequate study of the stilohyoid chain and Eagle's Syndrome.

Another discussed point on the stylohyoid chain is related to the pattern of calcification of the styloid process and stylohyoid ligament. Although there are studies classifying the places of calcification and ossification, there are missing information in literature regarding the relationship between the increase in the calcification of ligament and bone metabolism and processes of individuals. Therefore, studies on this field have yet to be performed since the etiology of the calcification and elongation of the styloid process are still not fully understood. This study investigated a possible correlation between the intensity of TMD symptoms and styloid process elongation and calcification by analyzing the styloid process length from measurements obtained on panoramic and lateral cephalometric radiographs, and using the morphological classification proposed by Langlais (7). The existence of differences between the measurements obtained from panoramic and cephalometric radiographs was also assessed.

\section{MATERIAL AND METHODS}

The project involved 50 patients referred for treatment of orofacial pain and was approved by the institutional Ethics Committee (Protocol \#2008.1.1058.58.3). The patients had been screened for the Service Occlusion and Temporomandibular Joint Dysfunction (SODAT/FORP-USP), all presenting symptoms relevant to TMD and orofacial pain for more than 3 months.

Patients were randomly selected to participate, with more females in the sample $(n=42 ; 84 \%)$, and were aged from 25 to 70 years. In order to avoid exposure to radiation, patients suspected to have, diagnosed with or under treatment for any kind of neoplastic tumor as well as pregnant women or suspected of pregnancy were excluded from the study.

A single previously calibrated and trained examiner performed the clinical and radiographic examinations in order to obtain reproducible results and higher reliability. The radiographs were numbered by a second person so that there was no identification by the researcher. Moreover, the radiographic analysis and measurements were performed 3 consecutive times at 1-month intervals in order to avoid memorization of measurements and radiographic images.

All subjects responded and were examined clinically, according to the Research Diagnostic Criteria for Temporomandibular Disorders - RDC/TMD axis I (8). Clinical assessment involved the measurement of mandibular movements and deviation from midline using a digital caliper, as well as palpation of the masticatory muscles and TMJ (Table 1) to check the presence of pain and joint sounds.

The presence of pain and dysfunction of the masticatory muscles was evaluated according to individual's responses to palpation. A previous study has standardized the areas that should be explored and even pressure to be applied in order to provide homogeneous criteria diagnoses for clinicians and researchers (8). This is particularly important to the reliability of results obtained in studies involving muscle palpation.

The patients indicated the presence or absence of pain on palpation, giving scores according to the RDC/ TMD, as follows: 0 no pain or just pressure, 1: mild pain, 2: moderate pain, and 3: severe pain. Next, patients were evaluated using the visual analog scale (VAS) (Table 2) in order to identify four common symptoms of TMD in Eagle's Syndrome, pre-selected based on clinical case reports.

The correlation with measurements in the stylohyoid chain was performed among the groups in such a way that it was possible to determine a possible association between the existence of a morphological

Table 1. Region palpated during RDC and the applied force in kilograms.

\begin{tabular}{lc}
\hline Region & Applied force $(\mathrm{kg})$ \\
\hline Posterior temporal & 1.0 \\
Medium temporal & 1.0 \\
Anterior temporal & 1.0 \\
Superior masseter & 1.0 \\
Medium masseter & 1.0 \\
Lower masseter & 1.0 \\
Mandibular posterior region & 0.5 \\
Submandibular & 0.5 \\
Area of the lateral pterygoid & 0.5 \\
Temporal tendon & 0.5 \\
Lateral pole of TMJ & 0.5 \\
Posterior ligament of TMJ & 0.5 \\
\hline
\end{tabular}

TMJ: temporomandibular joint. 
change in the stylohyoid chain and the intensity of pain in patients with TMD.

A digital panoramic radiograph for analysis of the styloid process length and shape and a digital lateral cephalometric radiograph for analysis of the styloid process length were requested.

The radiographic techniques employed were performed at the Ribeirão Preto Dental School Radiology Clinic under the supervision of an Occlusion Professor and a radiographer, according to all biosecurity criteria (protecting the operator and the patient) according to the Radiation Protection Basic Guidelines for Radiation Protection, dated August 1988 and approved by the National Nuclear Energy Commission (CNEN) and Ordinance 453, National Health Surveillance Agency (ANVISA), Ministry of Health, 1998. The technique was used for direct digital radiography, in which the image recording plate was obtained in charge couple device (CCD), which reduces by $60 \%$ the dose of exposure to $\mathrm{x}$ radiation.

The analysis of radiographs was performed using the Radiocef software (Radiomemory Ltda., Belo Horizonte, MG, Brazil), using a specific cephalometric analysis and linear measurements of the styloid process. Each radiograph was traced and measured three times, with intervals of 1 month between the measurements and the means were then examined in order to reduce the error between measurements.

Measurements were made on the radiographic images in the region of the hyoid-string style, bilaterally, with the aid of the software Radioimp (Radiomemory Ltda, version 2.0). After the images are properly calibrated, the program displays the image that is selected for analysis and allows adjusting brightness and contrast to increase the visualization of region and the accuracy of measurements (Fig. 1). The measurement is recorded automatically when the program displays the individual values for in each patient. The zoom tool was also used to magnify the displayed region and facilitate making

Table 2. Number of patients with pain according to the VAS scale.

\begin{tabular}{lccc}
\hline Symptoms & $\begin{array}{c}\text { Mild pain } \\
(0-3)\end{array}$ & $\begin{array}{c}\text { Moderate } \\
\text { pain (4-6) }\end{array}$ & $\begin{array}{c}\text { Severe } \\
\text { pain (7-10) }\end{array}$ \\
\hline Orofacial pain & 14 & 19 & 17 \\
Headache & 13 & 15 & 22 \\
Tinnitus & 21 & 18 & 11 \\
Vertigo and dizziness & 26 & 12 & 12 \\
\hline
\end{tabular}

the measurements, since these values are around $0.3 \mathrm{~cm}$

To measure the length of the styloid process bilaterally in the panoramic radiographs, zoom was given to the image to identify the region of the styloid process. Then, i was identified and drawn the outline of the external auditory canal bilaterally with the aid of the brightness and contrast adjustments. It was then traced under a horizontal line the lowest point of the contour of the acoustic meatus. Subsequently, it was measured the length of the styloid process, through a line segment extending from translating straight from the lowest point of the external acoustic meatus to the apex of the process (Fig. 2).

The data resulting from the styloid process length were statistically related to the symptoms (orofacial pain, headaches, tinnitus and vertigo) in order to observe the elongation of the styloid process is related to the increase in pain symptoms.

The same methodology used for the panoramic radiographs was used for the lateral cephalometric radiographs. It was identified and traced external acoustic meatus and then traced a line segment that was the apex of the styloid process to the horizontal line under the lowest point of the external acoustic meatus (Fig. 3 ). The styloid process length data obtained from the cephalometric radiographs was statistically compared with the data obtained from of panoramic radiography.

Still based on radiographic images, classification of styloid process elongation was made according to the classification proposed by Langlais (7), who developed a classification for the elongated styloid process, according to their radiographic presentation (Fig. 4). Radiographs of the styloid process were classified into the three

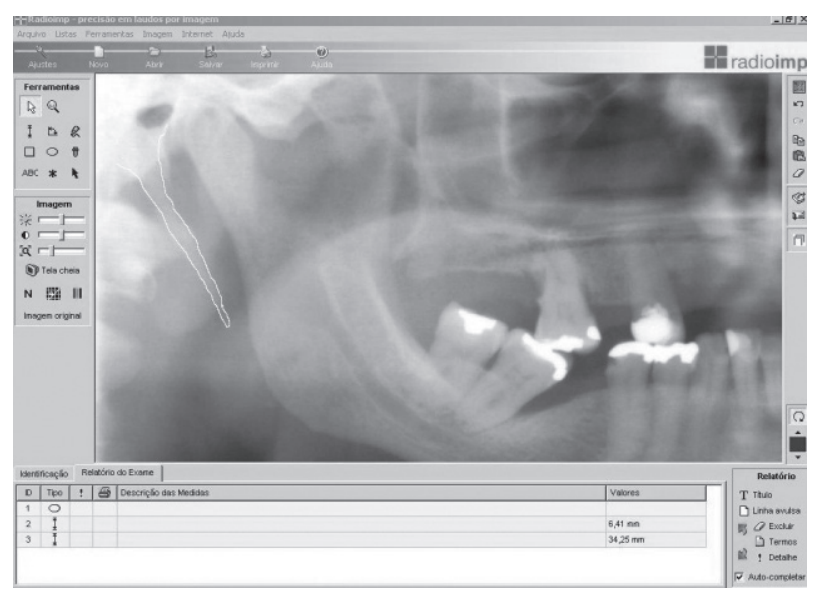

Figure 1. Image calibration by brightness and contrast. 
types (1 to 3 ) according to the degree of elongation, based on Langlais (7), and a type 0 was also included, which meant normal styloid process (Tables 3 and 4). This classification allowed evaluating the incidence of morphological styloid process in the sample.

The styloid processes analyzed in the radiographs were also classified according to the calcification pattern into four types (Fig. 5 and Table 5): A: External Calcification (boundary): image of the styloid process continuous, with no signs of calcification. B: Partial Calcification: image of the styloid process with the

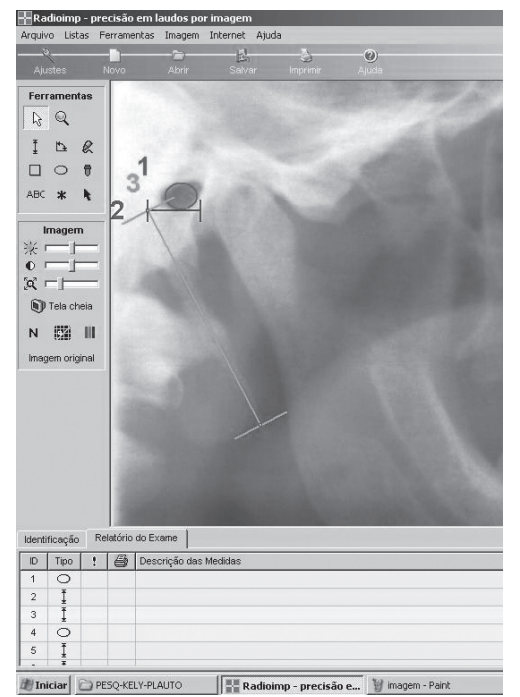

Figure 2. Measurement of the length of the styloid process on panoramic radiograph.

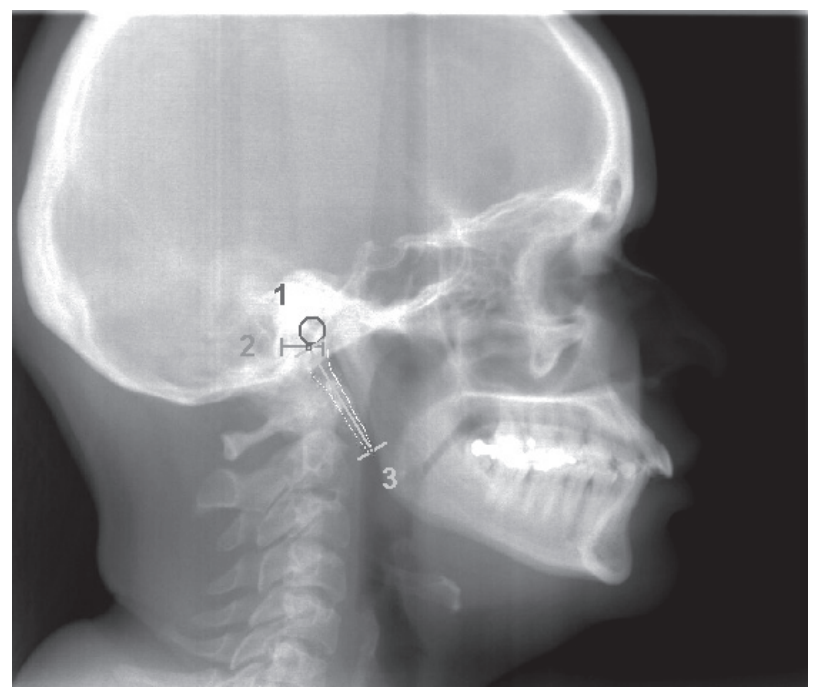

Figure 3. Measurement of the length of the styloid process on cephalometric radiograph. presence of radiopaque calcified segments. C: Nodular calcification: styloid process image with nodular areas, radiopaque calcification. D: Completely calcified: image of the styloid process radiopaque, calcified or totally homogeneous.

After performing of all measurements and assessments, data were analyzed statistically using BioStat 4.0 software.

\section{RESULTS}

The time between the occurrence of symptoms and onset of pain symptoms ranged around 1-20 years, and 16 subjects (32\%) claimed to feel orofacial pain for 10 years or more. On the frequency of pain, 20 subjects $(40 \%)$ had orofacial pain all the time and $30(60 \%)$ reported that the pain comes and goes. On the current pain, the scores were between 3-8 points in VAS scale. Another database was collected during the interview (Tables 6 and 7).

In the clinical evaluation, 10 subjects $(20 \%)$ had mouth opening limitation $(<40 \mathrm{~mm})$ and the vast majority showed deviation from the mean and standard deviation with opening.

Joint sounds were assessed by performing palpation and auscultation of the joints through the stethoscope during opening and closing the jaw, as well as by measurements of mandibular movements. As a result, 26 individuals (52\%) had some noise in the joint during the clinical examination, with cracking being the most prevalent noise, followed by coarse crepitus and fine crepitus.

Regarding the assessment of symptoms (orofacial pain, headaches, tinnitus and vertigo) obtained with the VAS scale, orofacial pain was the most common

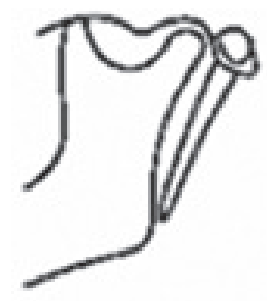

Elongate

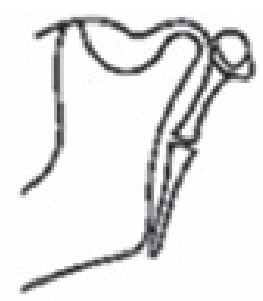

Pseude

\section{Segmented}

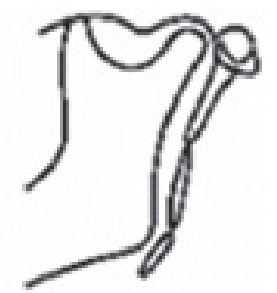

Segmented
Figure 4. Morphological classification proposed by Langais (1986). 
symptom (100\%), followed by headache (92\%), tinnitus $(76 \%)$ and dizziness $(72 \%)$. The first data to be analyzed were the values of the length of the styloid process bilaterally on the panoramic radiographs, showing the three measurements and the mean of these values. Measurements the length of the styloid process ranged from 14.32 to $67.81 \mathrm{~mm}$ on the right side (mean value of $32.98 \mathrm{~mm}$ ), and from 15.76 to $58.95 \mathrm{~mm}$ on the left side (mean value of $33.50 \mathrm{~mm}$ ).

Seventy-six percent of individuals had at least one of the styloid processes elongated, and there was variation in the distribution of occurrence of normal process $(24 \%)$, unilateral elongation $(22 \%)$ or bilateral (54\%) elongation.

To analyze the variance between the three measurements of the length of the styloid process on the right side and on the left side, correlation was made by Pearson's correlation. By this test, it is possible to obtain the correlation between the data, as a result ranging from -1 to 1 . The closer the Pearson's coefficient (r) is to 1 , the stronger the association between the data.

In this first analysis, it was observed a very strong association among the three measurements on each side, with Pearson's correlation coefficient $(\mathrm{r}=0.99)$, which shows a low error among them. It was also observed that for the three measurements in both the right and the left, scores were very close, which translates into greater reliability of the data.

After verification of the strong correlation and reliability of the data, it was analyzed the relationship between the length of the styloid process found on the right and left. It was found a slight tendency to the occurrence of elongation in the left side (68\%). As a result, it was found a Pearson's correlation coefficient of $r=0.8108$ and $p>0.01$, indicating that, although numerically different, there was no significant difference between measurements of left and right in this population.

In the cephalometric radiographs, the data resulting from measuring the length of the styloid process also demonstrated values with low variation between measurements and high data reliability, with Pearson's correlation coefficient (r) very close to $0.99\left(1^{\text {st }}\right.$ and $2^{\text {nd }}$ analysis: $0.9895 ; 1^{\text {st }}$ and $3^{\text {rd }}$ analysis: $0.9931,2^{\text {nd }}$ and $3^{\text {rd }}$ analysis: 0.9935). The styloid length measurements in cephalometric radiography ranged from $15.06 \mathrm{~mm}$ to $62.08 \mathrm{~mm}$ (mean value of $32.39 \mathrm{~mm}$ ).

Pearson's correlation was used again to determine if there was correlation between the lengths of the styloid process measured on panoramic radiographs with the lengths measured on cephalometric radiographs.

The correlation was made with the mean length of the styloid process of the right side measured on panoramic radiographs and the mean length of the styloid process measured on the cephalometric radiographs. The result was a high Pearson's correlation coefficient $(r=0.9825$ and $p<0.0001)$. This indicates that there is a high correlation and so measurements of the length of the styloid process on the panoramic radiograph obtained were similar to measurements on cephalometric radiographs.

It is worth mentioning that, due to geometric

Table 4. Distribution of patients according to the morphology of the styloid process (Langais, 1986).

\begin{tabular}{cc}
\hline Type of morphology & Percentage of subjects \\
\hline 0 & $34 \%$ \\
1 & $54 \%$ \\
2 & $19 \%$ \\
3 & $4 \%$ \\
\hline
\end{tabular}

Table 3. Classification according to styloid process elongation.

\begin{tabular}{|c|c|}
\hline Type & Characteristics \\
\hline Type 0 (Normal) & Styloid process is not elongated, with length less than $30 \mathrm{~mm}$ \\
\hline Type 1 (Elongated) & Styloid process uninterrupted and integrity of the image with a length greater than $30 \mathrm{~mm}$ \\
\hline $\begin{array}{l}\text { Type } 2 \text { (Pseudo- } \\
\text { segmented) }\end{array}$ & $\begin{array}{l}\text { Styloid process is apparently linked to the stylohyoid ligament mineralization, usually located above the } \\
\text { level touches the bottom edge of the jaw, giving an appearance of an elongated styloid process articulated. }\end{array}$ \\
\hline Type 3 (Segmented) & $\begin{array}{l}\text { Consists of a long (greater than } 30 \mathrm{~mm} \text { ), formed by short discontinuous portions of the styloid process. } \\
\text { Two or more segments are seen as interruptions above or below the level of the bottom of the jaw, or both. }\end{array}$ \\
\hline
\end{tabular}


factors, cephalometric radiographs provide better radiographic position and lower distortion, resulting in values closer to the real (9). In the present study, the measurements obtained from the cephalometric radiographs resulted in lower values for the styloid process.

Measurements of the length of the styloid process were also correlated between the three groups with different pain intensity. ANOVA and Tukey's test were used for data analysis, using the mean length of the styloid process of the groups. A significance level of $5 \%$ was adopted.

In this way, it could be observed that the elongated styloid process interfere with the severity of symptoms. Due to the location of the styloid process, theoretically according to its position (length), the apex of the process can press blood vessels and nerves causing pain.

Data from the styloid process length obtained from measurements on panoramic radiographs were correlated between the groups with "severe pain", "moderate pain" and "mild pain" separately for each of the symptoms (orofacial pain, headaches, tinnitus and

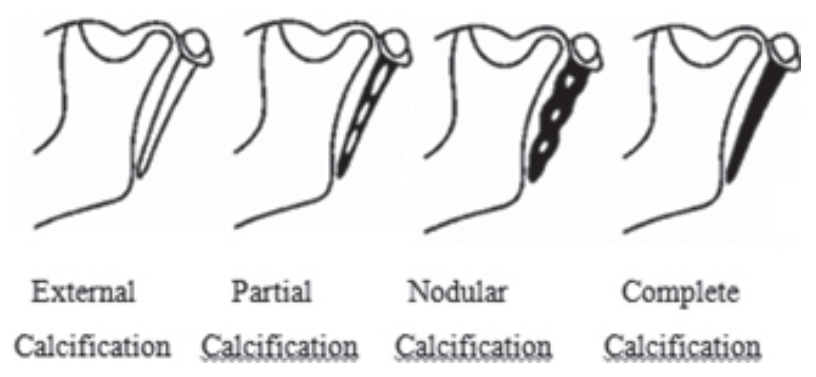

Figure 5. Calcification classification proposed by Langais (1986).

Table 6. Database collected during the interview.

\begin{tabular}{lc}
\hline Signs and symptoms & $\begin{array}{c}\text { Number of } \\
\text { patients }\end{array}$ \\
\hline Lock jaw & $11(22 \%)$ \\
$\begin{array}{l}\text { Habit of grinding or clenching your teeth } \\
\text { while sleeping }\end{array}$ & $35(70 \%)$ \\
$\begin{array}{l}\text { Habit of grinding or clenching your teeth } \\
\text { during the day }\end{array}$ & $30(60 \%)$ \\
$\begin{array}{l}\text { Feel tired when you wake up } \\
\text { Rheumatoid arthritis or another disease } \\
\text { that can affect joints }\end{array}$ & $40(80 \%)$ \\
\begin{tabular}{l} 
Stroke or trauma to the face jaw \\
\hline
\end{tabular} & $11(22 \%)$ \\
\hline
\end{tabular}

vertigo). The results were the values $p>0.05$. Therefore, there was no statistically significant difference between the styloid process length and intensity of symptoms in both groups.

\section{DISCUSSION}

The results of this study showed the prevalence of alterations in the morphology of the styloid process in patients with TMD. It was observed that $76 \%$ of the individuals showed elongation of at least one of the styloid processes and only $24 \%$ did not. Similar percentages of elongation of the styloid process and calcification have been reported (10). These data show that the elongation of the styloid process should not be considered a rare finding in adults and greater importance should be given to study these changes. Especially in patients with TMD, the incidence of elongation appears to be higher.

In agreement with other authors, it is recommended that in case of confirmation of mineralization and stretch in the styloid chain, radiographic analysis should be done to obtain complete analysis of the styloid process at various levels $(11,12)$ and detailed patient history. Therefore, the importance of the radiographs analysis in these studies. Panoramic radiology was not included as an option for image original DTM in the DRC, but has been recommended as a screening tool for TMJ pathology (13). Ahmad (14), to improve operational specification of the RDC/TMD, proposes the analysis

Table 5. Distribution of patients according to the calcification of the styloid process (Langais, 1986).

\begin{tabular}{lc}
\hline Type of calcification & Percentage of subjects \\
\hline External calcification & $59 \%$ \\
Partial calcification & $19 \%$ \\
Nodular calcification & $8 \%$ \\
Completely calcified & $14 \%$ \\
\hline
\end{tabular}

Table 7. Number of patients with pain in clinical evaluation.

\begin{tabular}{lc}
\hline Clinical evaluation & Number of patients \\
\hline Joint pain & 24 \\
Muscles pain & 22 \\
Pain in both & 4 \\
\hline
\end{tabular}


of panoramic radiographs, magnetic resonance and computed tomography scan to evaluate the ATM.

With respect to accuracy and reproducibility of measurements by Pearson's correlation, it was noted that all measurements were reproducible with low error between the intervals of measurements.

In the case of radiographs, it is known that the cephalometric radiographs are considered more reliable (15) compared with panoramic radiographs, suffering less distortion and revealing a closer picture of the real (9). In the present study, it was found that the measurements of the length of the styloid process performed between the types of radiographs (panoramic radiographs and lateral cephalometric radiographs) were similar in other words, there was no statistically significant difference between them. This is a good result because although the panoramic image can be more affected by distortions due to the greater sensitivity of the technique to positioning (16), it was concluded that it is rather a valuable tool for the analysis of styloid process.

This study provided evidence of the impact of morphological changes in the styloid chain in patients with TMD, and thus can classify the type of stretching and pattern of calcification.

The mean lengths of the right and left styloid processes were $33.50 \mathrm{~mm}$ and $32.98 \mathrm{~mm}$, respectively. Another study showed that there is a variation in length from 15.2 to $60 \mathrm{~mm}$ (17) (mean value of 2 to $3.2 \mathrm{~cm}$ ) (18).

In the same way of the present study, $54 \%$ of bilateral elongation versus $22 \%$ of unilateral elongation, other authors also found a predominance of bilateral stretching $(10,18,19)$.

It was also observed in this study the relationship between the length of the styloid process on the right and left sides and is therefore statistically similar, which confirms the findings of Kaufman (19). The result was different from those of Guo et al. (20), who found the occurrence of bilateral ossification, but not necessarily the two sides are symmetrical. In the examined individuals, we could see a slight tendency to stretch the left side, since we find 34 elongated styloid process on the left and 31 right side of the elongated processes. This result was similar to Ferrario et al. (10) also found that predisposition to stretching the left side.

The results of this study indicated a high prevalence of elongation/calcification of the styloid process $(76 \%)$ in patients with TMD, also confirmed by Krennmair and Piehslinger (21).

Some authors affirm that the ossification of the styloid complex can reduce jaw movement (21), however it was observed, even though most had ossification of the stilohyoid chain, only 10 patients (20\%) had limited opening $(<40 \mathrm{~mm}), 3$ of which showed no ossification styloid complex. Therefore, it was possible that in the sample, the jaw movement was not affected by the presence of ossification of the stilohyoid chain.

During the interview, $100 \%$ of patients had orofacial pain, $92 \%$ had headache, $76 \%$ had some degree of tinnitus and $72 \%$ had some degree of vertigo. These results reproduced what is normally found in the literature and were similar to those of Cooper and Kleinberg (22), who analyzed 4,528 patients screened for the treatment of TMD and observed through a questionnaire, the prevalence of same symptoms. Among the symptoms were found: pain (96.1\% of subjects), headache $(79.3 \%)$, and ear discomfort or dysfunction (82.4\%). Studies in the general population show that the mean prevalence of tinnitus in patients with TMD varies from $28 \%$ to $76 \%$ (23), while dizziness associated with TMD range from $5 \%$ to $70 \%$ (24).

About the length, it was observed that the group with greater intensity of orofacial pain (severe pain group) had longer styloid process than the group of mild pain. The same occurred for headache, tinnitus and vertigo. Although no statistically significant difference was found, the length of the styloid process may have some influence on the intensity of symptoms.

In conclusion, no statistically significant association was found between the morphological changes in the length of the styloid process and symptoms of TMD (orofacial pain, headaches, tinnitus and vertigo). However, by analyzing the means and standard deviations of the measurements performed in the styloid chain there was a tendency to greater lengths of the styloid process in patients with higher pain intensity, especially for tinnitus. In addition, measurements of the length of the styloid process on panoramic radiographs were statistically similar to those obtained on cephalometric radiographs.

\section{RESUMO}

O conhecimento adquirido sobre a síndrome de Eagle demonstra que sua sintomatologia pode ser confundida muito facilmente com outros tipos de desordens craniomandibulares, principalmente a disfunção temporomandibular (DTM). O objetivo do estudo foi encontrar uma possível correlação entre a presença de DTM e o alongamento do processo estilóide, assim como a relação com a calcificação da cadeia estilo-hiódea. Para tanto foram analisados 50 pacientes com DTM, confirmada a partir do RDC/TMD. 
Foi realizado o exame clínico e documentação radiográfica de cada paciente, composta por: radiografia panorâmica digital e cefalométrica lateral digital. Para a análise das radiografias foi utilizado o programa computacional Radiocef (Radiomemory), onde foram realizados traçados cefalométricos por análise específica e medidas lineares do processo estilóide. Cada radiografia foi traçada e medida por três vezes, com intervalos de tempo de 1 mês entre as medições a fim de diluir o erro. Foi realizada a estatística através do Programa Biostat 4.0 e o teste de Pearson ( $\mathrm{p}=0,001)$. Como resultado foi encontrada uma incidência de $76 \%$ de alongamento do processo estilóide na amostra. Houve correlação positiva para as medidas bilaterais realizadas na radiografias panorâmicas $(\mathrm{p}<0,001)$ e também para as medidas de comprimento do processo estilóide realizados nas diferentes tomadas radiográficas panorâmicas e cefalométricas laterais $(\mathrm{p}<0,001)$. Concluiu-se que há prevalência de alongamento do processo estilóide em pacientes com DTM, embora não tenha sido encontrada relação entre as medidas realizadas na cadeia estilo-hióidea com os sintomas de cefaléia, dor orofacial, zumbido e vertigem.

\section{ACKNOWLEDGEMENTS}

The authors are indebted for the financial support granted by CAPES.

\section{REFERENCES}

1. Atsu SS, Ayhan-Ardic F. Temporomandibular disorders seen in rheumatology practices: a review. Rheumatol Int 2006;26:781787.

2. De Leeuw R. Orofacial pain: guidelines for assessment, diagnosis and management. The American Academy of Orofacial Pain. Chicago: Quintessence Int 2008;4:2-5.

3. Hotta PT, Hotta TH, Bataglion C, Pavão RF, Siéssere S, Regalo SC. Bite force in temporomandibular dysfunction (TMD) and healthy complete denture wearers. Braz Dent J 2008;19:354-357.

4. Tuz HH, Onder EM, Kisnisci RS. Prevalence of otologic complaints in patients with temporomandibular disorder. Am J Orthod Dentofacial Orthop 2003;123:620-623.

5. Bernhardt O, Gesch D, Schwahn C, Bitter K, Mundt T, Mack F, et al.. Signs of temporomandibular disorders in tinnitus patients and in a population-based group of volunteers: results of the Study of Health in Pomerania. J Oral Rehabil 2004;31:311-319.

6. Pereira FL, Iwaki Filho L, Pavan AJ, Farah GJ, Gonçalves EAL, Veltrini VC, et al.. Styloid-Stylohyoid Syndrome: literature review and case report. J Oral Maxillofac Surg 2007;65:1346-1353.

7. Langlais RP, Miles DA, Van Dis ML. Elongated and mineralized stylohyoid ligament complex: a proposed classification and a report of a case of Eagle's syndrome. Oral Surg Oral Med Oral Pathol 1986;61:527-532.

8. Dworkin SF, Leresche L. Research diagnostic criteria for temporomandibular disorders: review, criteria, examinations and specifications. J Craniomandib Disord 1992;6:301-355.
9. Ongkozowito EM, Dieleman MMJ, Kuijpers-Jagtman AM, Mulder PGH, Van Deck JW. Linear mandibular measurements: comparison between orthopantomograms and lateral cephalograms. Cleft Palate Craniofac J 2009;46:147-153.

10. Ferrario VF, Sigurta D, Daddona A, Dalloca L, Miani A, Tafuro F, et al.. Calcification of the stylohyoid ligament: incidence and morphoquantitative evaluations. Oral Surg Oral Med Oral Pathol 1990;69:524-529.

11. Eagle WW. Symptomatic elongated styloid process: report of two cases of styloid process-carotid artery syndrome with operation. Arch Otolaryngol 1949;49:490-503.

12. Gossman JR Jr, Tarsitano JJ. The styloid-stylohyoid syndrome. J Oral Surg 1977;35:555-560.

13. Kononen M, Kilpinen E. Comparison of three radiographic methods in screening of temporomandibular joint involvement in patients with psoriatic arthritis. Acta Odontol Scand 1990;48:271277.

14. Ahmad M, Hollender L, Anderson Q, Kartha K, Ohrbach RK, Truelove EL, et al.. Research diagnostic criteria for temporomandibular disorders (RDC/TMD): development of image analysis criteria and examiner reliability for image analysis. Oral Surg Oral Med Oral Pathol Oral Radiol Endod 2009; 107:844860.

15. Houston WJB. The analysis of errors in orthodontic measurements. Am J Orthod Dentofac Orthop 1983;83:382-390.

16. Kambylafkas P, Murdock E, Gilda E, Tallents RH, Kyrkanides S. Validity of panoramic radiographs for measuring mandibular asymmetry. Angle Orthod 2006;76:388-393.

17. Balbuena L Jr, Hayes D, Ramirez SG, Johnson R. Eagle's Syndrome (elongated styloid process). South Med J 1997;90:331334.

18. Gozil R, Yener N, Calguner E, Arac M, Tunc E, Bahcelioglu M. Morphological characteristics of styloid process evaluated by computerized axial tomography. Ann Anat 2001;183:527-535.

19. Kaufman SM, Elzay RP, Irish EF. Styloid process variation. Radiologic and clinical study. Arch Otolaryngol 1970;91:460-463.

20. Guo B, Jaovisidha S, Sartoris DJ, Kyung NR, Berthiaume MJ, Clopton P, et al.. Correlation between ossification of the stylohyoid ligament and osteophytes of the cervical spine. J Rheumatol 1997;24:1575-1581.

21. Krennmair G, Piehslinger E. The incidence and influence of abnormal styloid conditions on the etiology of craniomandibular functional disorders. Cranio 1999;17:247-253.

22. Cooper BC, Kleinberg I. Examination of a large patient population for the presence of symptoms and signs of temporomandibular disorders. Cranio 2007;25:114-126.

23. Camparis CM, Formigoni G, Teixeira MJ, De Siqueira JT. Clinical evaluation of tinnitus in patients with sleep bruxism: prevalence and characteristics. J Oral Rehabil 2005;32:808-814.

24. Urban VM, Neppelenbroek KH, Pavan S, Alencar Júnior FGP, Jorge JH, Almilhatti HJ. Association between otalgia, tinnitus, vertigo and hypoacusia, with temporomandibular disorders. RGO 2009;57:107-115.
Received May 20, 2012

Accepted September 25, 2012 